\title{
The Mechanical Performance Analysis of SPS Orthotropic Laminated Steel Bridge Panel
}

\author{
Lixin Xia ${ }^{1, a}$, Pu Ke $e^{2, b}$, Bin Xie ${ }^{1, c}$, Doukao Jia ${ }^{2, d}$, and MuhammadTursun \\ Abdureyim ${ }^{*}, \mathrm{e}$
${ }^{1}$ Kashgar University, College of Physics and Electrical Engineering, China
2 Kashgar University, College of Civil Engineering, China
axialx0227@126.com, b kepu1989@163.com, c389276517@qq.com,d1196455778@qq.com, \\ e1216749379@qq.com
}

Keywords: SPS sandwich panel; Orthotropic steel deck plate; Finite element method; Maximum Principal Stress

Abstract. To establish a space finite element model of SPS steel orthotropic sandwich structure bridge panel and ordinary steel orthotropic bridge, compare the extreme value distribution and size of two orthotropic bridge decks under different stress states and the stress of the structures, and analyze the stress performance differences of two bridge panels. The results show that comparing to the ordinary orthotropic steel bridge panel, the mechanical performance of SPS steel orthotropic sandwich structure bridge panel is more reliable.

\section{Introduction}

SPS Sandwich plate has many advantages such as light weight, large rigidity, high strength and convenient for construction. Sandwich plate has been introduced to bridge structure in recent years, and developed countries are doing theoretical and experimental research. Will SPS board is used to replace the traditional orthotropic steel bridge deck plate. The sandwich orthotropic steel bridge panel is a compound structure formed by putting higher elastic modulus of polyurethane core body between two layers of steel plates, It belongs to a sandwich plate system, SPS, and it can bear a lot of vertical load of the plate and needs minimal stiffener. The orthotropic steel deck plate is not only used in ship building, repair and reinforcement, but also used in civil engineering ${ }^{[3]}$. However, because of the core layer has a certain stiffness, and the stress is not zero, according to the internal force equilibrium equation of micro element and deformation coordination conditions such as establishing the differential equation of the stress and displacement, it is complex to use theory method to study the orthotropic laminated bridge panel deformation even without considering the stress condition of core layer. It is complicated even using the energy principle and variational method to establish the differential equation, the elastic support stiffness is different form two sides of the bridge panel, and the complex boundary conditions of vertical continuous elastic is difficult to solve directly, nowadays it is more common to use the numerical simulation.

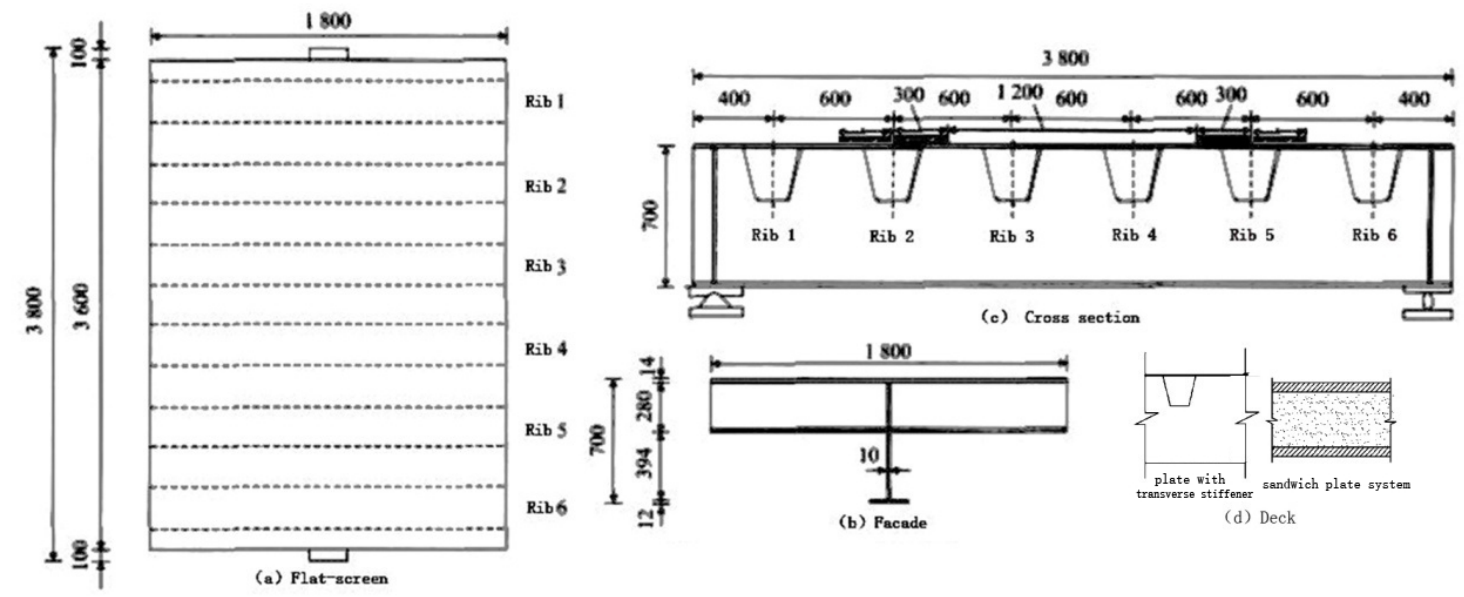

Fig. 1 Dimensions of the Full-scale Test Model and the Stiffening Ribs [mm] 


\section{Analysis Method and Finite Element Calculation Model}

Structural Parameters of the Model. A long-span bridge the specimen of the full-scale model of orthotropic steel bridge panel, As shown in figure 1: Mainly formed by the cover plate, longitudinal and transverse clapboard welding, including the main structure of the steel bridge deck. Keep the longitudinal rib openings on the $300 \mathrm{~mm}, 280 \mathrm{~mm}$, longitudinal silent stiffener size is $300 \times 280 \times 8$ $\mathrm{mm}$ and keep chamfering radius the same, and adopt grade Q345B steel. SPS orthotropic laminated steel bridge deck uses SPS plate the specification for 7-40-7 (mm) ${ }^{[4]}$ as bridge panel (as shown in figure $1-d)$ to keep the thickness of two steel bridge panels equal. SPS board core layer adopts the elastic modulus $\mathrm{E}=800 \mathrm{Mpa}$ polyurethane materials, Poisson's ratio $\mu=0.48$, defining the value of Shear modulus by $G=E /(2+2 \mu)$, due to severe polyurethane material density is only $1 / 200 \sim 1 / 150$ of steel, so the weight of SPS plate by split form is increased slightly compared with the original single piece of steel plate. The SPS orthotropic sandwich structure bridge panel and ordinary steel orthotropic bridge panel are numbered for I and II respectively in this paper.

Modeling Approach.The model of orthotropic steel deck plate with sandwich plate system is made of mixed finite elements for shell elements with body elements, and the upper and lower panels and the intermediate sandwich layer are all made of the body elements. The owned nodes by both is used at the interface between layers. The common orthotropic steel bridge deck plate is made of shell elements that all steel plates are simulated by plate elements. To simulate the stress condition of the actual bridge panel, The boundary condition of the practical bridge deck is simulated by the elastic support from the web plate and the diaphragm.

The boundary condition is the simulated bridge bearings with areas of $200 \times 300 \mathrm{~mm}$, at the two end cross sections of the model under simply supported constraints.

According to the vehicle $\mathrm{CH}-\mathrm{CL}$ in Chinese standard loading code (JTG_B01-2003), the load simulation uses double-point loading, with the loads applied to the deck surface on two $600 \times 300 \mathrm{~mm}$ areas with a clear distance between them of $1800 \mathrm{~mm}$, to simulate a single tire wheel load transmitted through pavement. The loaded areas are symmetrical about the center line of the model, and located directly above the side web plate of Rib 2 and Rib 5, as shown in Figure 1.

By referring to full-scale steel panel fatigue testing for the Bronx Whitestone Bridge and the Guang'an Busan Bridge ${ }^{[8.10]}$, in combination with finite element analysis results ${ }^{[9]}$ of stress distribution of the steel bridge decks we determine a load of $\mathrm{P}=250 \mathrm{kN}$.

Simulation software is used to establish a computational model, as shown in figure 2. (Due to limited space, this paper only shows the finite element model for the U-shaped cross section).

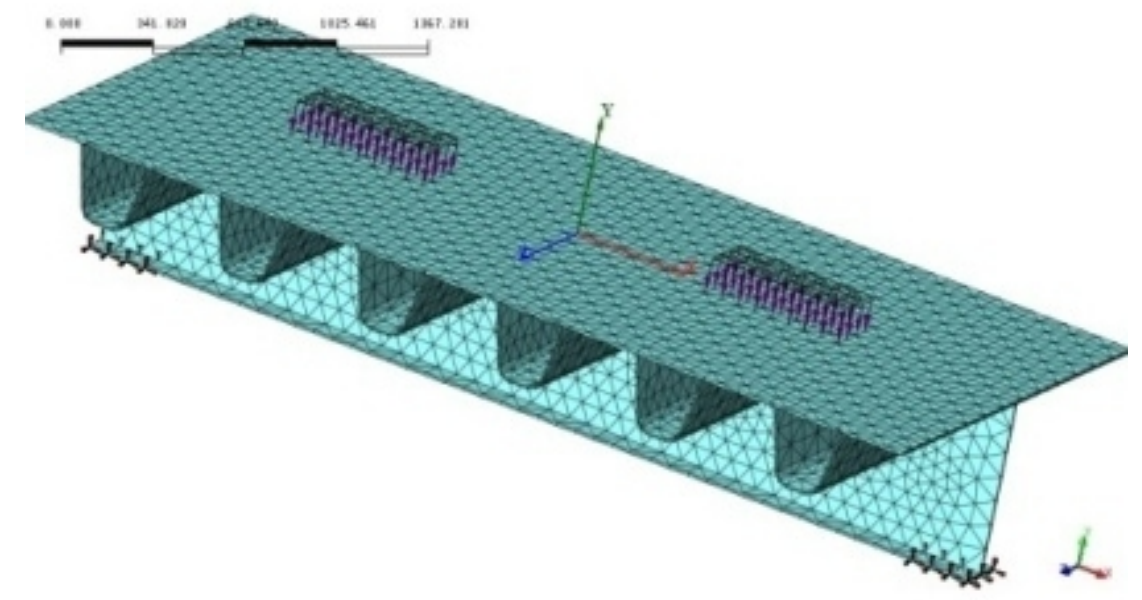

Fig. 2 Finite Element Model

Analysis of the Results. The corresponding stress levels of the bridge panel, the cross beam and the longitudinal rib are collected from the calculation results of two models in table 1. Data from table 1 shows that in the bridge panel I, the extremum size difference of the bridge panel, transverse diaphragm, and stress of the longitudinal rib is not big, so camparing to bridge panel II with a big 
peak stress difference, the stress distribution of bridge panel I is more reasonable. And the stress peak of bridge panel I is about one third to one half of II bridge panel, and it is concentrated in the area of diaphragm plate, as shown in figure 3 , that is the diaphragm plate stress distribution nephogram. The peak stresses of the two types of bridge decks are between rib 1 to 2 and rib 5 to 6 , that is the diaphragm plate bending shear coupling.

Table 1 Section of Stiffener is Different Form of Extreme Stress（MPa）

\begin{tabular}{|c|c|c|c|c|c|c|c|c|}
\hline \multirow{3}{*}{$\begin{array}{l}\text { Stress } \\
\text { type }\end{array}$} & \multicolumn{5}{|c|}{ bridge panel I } & \multicolumn{3}{|c|}{ bridge panel II } \\
\hline & \multicolumn{3}{|c|}{$\begin{array}{l}\text { The bridge panel (SPS } \\
\text { sandwich board) }\end{array}$} & \multirow[b]{2}{*}{$\begin{array}{l}\text { diaphragm } \\
\text { plate }\end{array}$} & \multirow[b]{2}{*}{$\begin{array}{l}\text { Longitudinal } \\
\text { rib }\end{array}$} & \multirow[b]{2}{*}{$\begin{array}{c}\text { Bridge } \\
\text { deck } \\
\text { slab }\end{array}$} & \multirow[b]{2}{*}{$\begin{array}{c}\text { Diaphragm } \\
\text { plate }\end{array}$} & \multirow[b]{2}{*}{$\begin{array}{l}\text { Longitudinal } \\
\text { rib }\end{array}$} \\
\hline & $\begin{array}{l}\text { The } \\
\text { upper } \\
\text { steel } \\
\text { plate }\end{array}$ & $\begin{array}{l}\text { Sandwich } \\
\text { layer }\end{array}$ & $\begin{array}{c}\text { The } \\
\text { lower } \\
\text { steel } \\
\text { plate }\end{array}$ & & & & & \\
\hline $\mathrm{P}_{1}$ & 3.72 & 0.95 & 5.88 & 4.98 & 6.09 & 3.86 & 11.77 & 13.08 \\
\hline $\mathrm{P}_{3}$ & -3.76 & -1.05 & -4.61 & 10.06 & -6.62 & -16.01 & -33.28 & -17.57 \\
\hline$\left|\sigma_{X}\right|_{\max }$ & 3.63 & 0.97 & 4.99 & 3.81 & 4.46 & 12.45 & 8.32 & 12.75 \\
\hline$\left|\sigma_{Y}\right|_{\max }$ & 0.33 & 1.04 & 0.84 & 6.72 & 4.12 & 2.46 & 15.71 & 11.13 \\
\hline
\end{tabular}

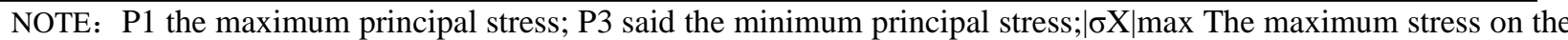
absolute value of $\mathrm{X}$ direction; The maximum stress on the absolute value of $\mathrm{Y}$ direction.

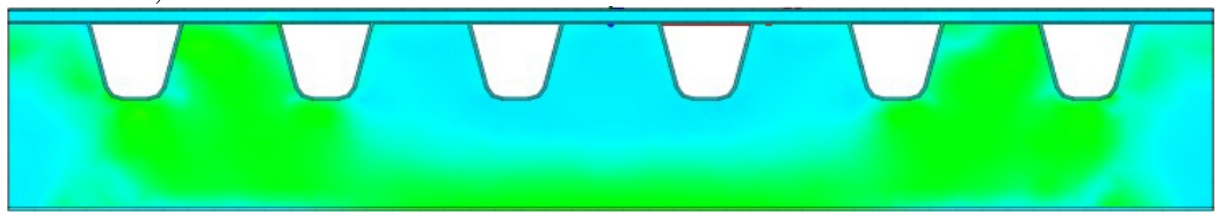

a) Principal stress nephogram of diaphragm plate in bridge panel I

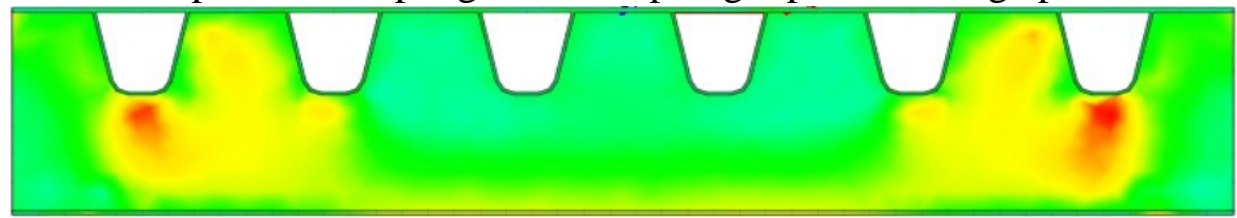

b ) Principal stress nephogram of diaphragm plate in bridge panel II

Fig. 3 Principal Stress Nephograms of Diaphragm Plate for the Two Kinds of Bridge Panel

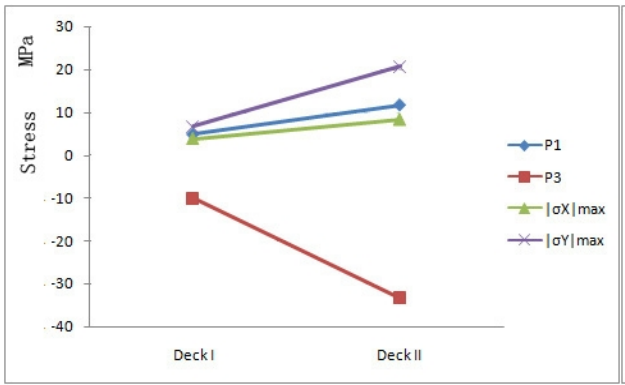

a) diaphragm plate

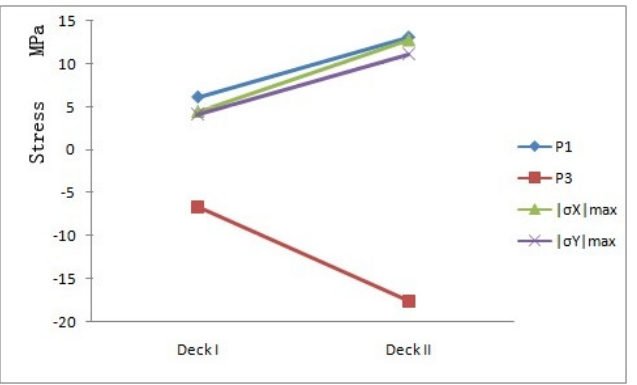

b ) Longitudinal rib

Fig. 4 Comparison of Extreme Stresses

According to the comparing trend of Figure 4, It was more obvious that the stress extreme value in Bridge deck ,transverse diaphragm and longitudinal rib of bridge panel I is significantly smaller than that of bridge panel II. So the basic judgment could be made that section II is more reasonable than the other one. 


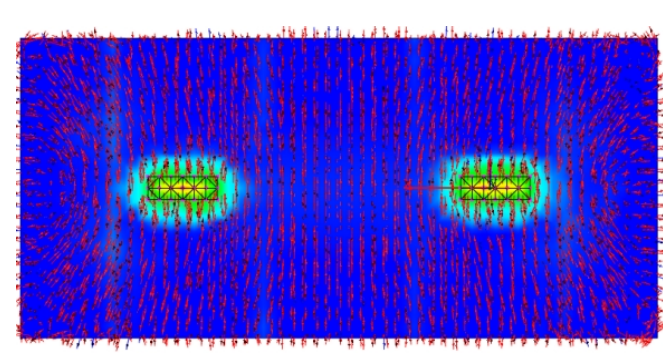

a) The upper steel plate

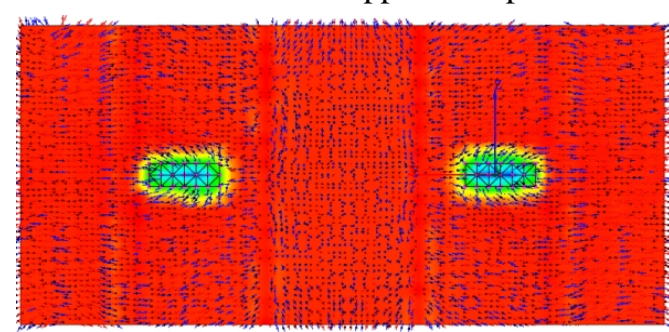

c) The Sandwich layer

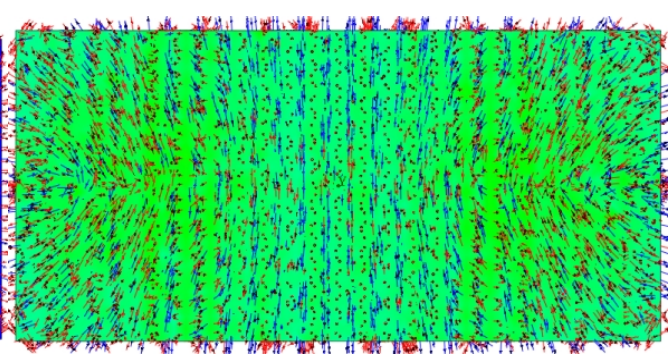

b) The ordinary bridge deck

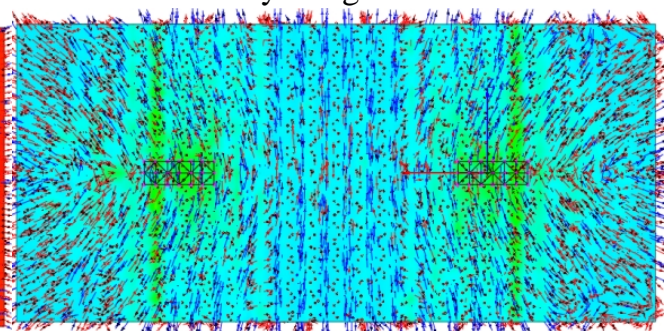

d) The lower steel plate

Fig. 5The Nephogram of the Distribution for Stresses

As shown in Figure 5,The stress extreme value of bridge panel is mainly distributed in local area where wheel load focuses. And the stress distribution of the ordinary bridge deck is more similar to that of the lower plate of the sandwich panel. A stress ring in space emerged around the outer ring of the local area where wheel load focuses. The stress of the upper plate in SPS sandwich board of bridge panel I is basically parallel to the bridge deck, except the part around the local area where wheel load focuses. And a stress ring in plane emerged around the outer ring of the local area where wheel load focuses. Due to the low rigidity and large flexibility of the sandwich layer, the stress is parallel to the axis Y. So $|\sigma y|_{\max }$ is the closest to the value of maximum principal stress. A rotating curved surface circling axis $\mathrm{Y}$ emerged around the outer ring of the local area where wheel load focuses. And it consist of millions of stresses.

\section{Conclusions}

By analyzing the two spatial finite element models, and comparing the cross section horizontal stress distributions affected by the local stresses at the different bridge panel wheel points. The results showed that:

(1) As same as the ordinary orthotropic plate, the peak stresses, were mainly found at the shear and bending connections of the components.

(2) The stress distribution of the ordinary bridge deck is similar to that of the lower plate of the SPS sandwich panel.

(3) Comparing to the ordinary orthotropic plate, sandwich panel bridge can significantly reduce the local stress concentration, the peak stress is about $1 / 2$ to $2 / 3$ less than the ordinary orthotropic steel bridge panel, so that it can significantly reduce the appearance of weld fatigue cracks;

(4) The stress of the upper plate in SPS sandwich board of bridge panel I is basically parallel to the bridge deck ,but that be around the local area where wheel load focuses. And a stress ring In plane emerged around the outer ring of the local area where wheel load focuses. The low rigidity and large flexibility of the sandwich layer contributes that the Stress is parallel to the axis Y.

The stress of the upper plate in SPS sandwich board of bridge panel I is basically parallel to the bridge deck ,except the part around the local area where wheel load focuses. Due to the low rigidity and large flexibility of the sandwich layer, the stress is parallel to the axis Y.

This work is supported by the National Science Foundation of China [grant number 11564020], the Person with Ability Study Foundation of Kashgar University (No. GCC14ZK-002), the research project of Kashgar University for youth (No. 13-2486). *Corresponding author: M.T. Abdureyim, 1216749379@qq.com 


\section{References}

[1] CHEN Xiao-dong, ZHOU Nan-qiao, ZHANG Hai. Study on the manufacturing technology of steels/polyurethane/steel sandwich plate [J]. China Plastics Industry, 2008, 36(4): 63-66.

[2] CHENG Bin, TANG Wei-li. Progress in research and Application of Sandwich Plate System in bridge deck [J]. Bridge Construction, 2015, 45(1): 13-19.

[3] TONON F, AMADEI B. Effect of Elastic Anisotropy on Tunnel Wall Displacements Behind at Tunnel Face [J]. International Journal of Rock Mechanics and Rock Engineering, 2002, 35(3): 141-160.

[4] SHAN Cheng-lin. Stress performance analysis on orthotropic steel bridge deck with Sandwich Plate System of and elastomer[J]. Journal of Hunan University (Natural Sciences), 2010, 37(12): $18-23$.

[5] Tian-long Zhao, Xing Fang, Ling Bai. The discussing on improved details of orthotropic steel bridge deck [J]. Railway Engineering, 2011（9）:24-28.

[6] YAN Fei, LIU Lin. Fatigue Life Analysis of closed Longitudinal Rib Sections on Stress Distribution of Orthotropic Decks [J]. China Municipal Engineering, 2000, 33 (3) : 16-21.

[7] Liang Quanfu, Shao Jonggan. Technology of reinforced simply supported hollow beam with transverse prestressing in Vitro [M]. Bei Jing: China Building Industry Press, 2007.

[8] Lingsen Yao. Bridge Engineering [M]. Bei Jing: China Communications Press,2008. in Chinese.

[9] Chunsheng Wang, Bingning Fu, Qin Zhang. The Full-scale Fatigue Test of Orthotropic Steel Bridge Panel [J]. China Journal of Highway and Transport.2013, 26 (2) 69-76. in Chinese.

[10] Quanfu Liang, Jinggan Shao. In Vitro Transverse Prestressing Reinforcement Technology Simply Supported Slabs Bridge [M]. Beijing. China Building Industry Press, 2007. in Chinese. 